\title{
COMMISSION 44: ASTRONOMICAL OBSERVATIONS FROM OUTSIDE THE TERRESTRIAL ATMOSPHERE (OBSERVATIONS ASTRONOMIQUES AU-DEHORS DE L'ATMOSPHËRE TERRESTRE)
}

\author{
Report of Meetings, 21, 22 and 28 August 1973
}

President: V. Prokof'ev.

SECRETARY: H. Lamers.

\section{Administrative Session}

The President gave a short review of recent results and a preview of future developments in space astronomy. He mentioned especially the planetary and interplanetary investigations, the solar observations by means of the OSO stations, Interkosmos satellites and Skylab, and the stellar observations by means of the OAO-2, TD-1A and OAO-3 satellites. The loss of the three Astronauts in USSR Dobrovolsky, Volkov and Patzaev was honoured by standing up and silence.

Colloquium 14 'UV and X-Ray Spectroscopy in Astrophysical and Laboratory Plasmas' in Utrecht in 1971, and Symposium 54 'Problems of Calibration of Absolute Magnitudes and Temperatures of Stars' in Geneva in 1972 were sponsored by Commission 44.

The following proposed Symposia and Colloquia will be sponsored by Commission 44: 'The Solar X-and Gamma-Radiation' in Buenos Aires to be held during the next COSPAR session in Brazil in 1974 (Commissions 10, 12 and 44), 'UV and X-Ray Spectroscopy of Astrophysical and Laboratory Plasmas' in Harvard Observatory on 9-11 September 1974 (Commission 14 and 44) and 'UV Spectra and Ground-Based Observations' in Utrecht, 1975 spring.

The Report of Commission 44 was prepared by the President with the addition of information obtained from A. Code, A. Dalgarno, A. Boggess and R. Bonnet. The information from G. A. Doschek and R. W. Noyes was received too late and therefore could not be added to the Report.

Before the election of the new President, Vice-President and Organizing Committee the chairman reported on some statistics on the membership of the Commission. There are two approximately equal groups of members working in the regions of solar and stellar space Astronomy. Therefore it will be worthwhile to nominate as President and Vice-President persons from these two groups respectively. A proposal was made to introduce in the Organizing Committee a specialist in the region of IR Astronomy, in particular P. J. Lena (Paris).

There was a discussion on the position of Commission 44 with respect to other Commissions of the IAU. Space research is well developed now and its work and results are included in various other Commissions dealing with specific topics (N. Roman). L. Gratton proposed that the technical matters should be dealt with in the Commission for instrumentation; however, Commission 9 is already too large. N. Roman proposed that Commission 9 should be divided in different groups. Commissions 44 and 9 should come together and redefine their tasks. A. Underhill thinks there is a reason to continue the work of Commission 44 in coordinating all space research and in cosponsoring the discussions with other Commissions; it is a place where the space researchers come together.

A discussion about scientific priorities (L. Goldberg, R. Lüst, A. Code, N. Roman, J. Jefferies, A. Underhill, A. Gabriel) led to the following conclusions:

Commission 44 shares its scientific problems with other IAU Commissions, as it covers such aspects as the Sun, the Solar System and Galactic and Extragalactic research. On one hand there are scientific problems connected with the nature of Solar events, which need X-and UV-spectra of the Sun, and systematic observations of the emission of active regions and flares on the Sun. This study is connected with observations of the events in interplanetary space. 
As regards stellar Astronomy from space, the spectral resolution in UV obtained by OAO-3 (Copernicus) $(0.1-0.05 \AA)$ is probably sufficient. It is necessary, however, to increase the sensitivity in order to record, both photometrically and spectrographically, UV and IR spectra of stars to limiting magnitudes fainter than 15 with sufficient spectral resolution. Further problems are: optical UV and IR observations and the identification of new stellar objects such as Pulsars, Quasars, and X-Ray Sources, and observations of UV and IR spectra of late-type stars in search for stellar chromospheres. Another high priority objective is diffraction-limited imaging with a powerful telescope, to be able to observe individual stars in galaxies.

The technical means for investigating all these problems are: Aircraft, Balloons, Rockets, Orbital Stations, Shuttle-Satellites or Free Flyers, and Interplanetary Probes.

\section{Scientific Sessions, 22 and 28 August 1973}

THE SOLAR X-RAY AND UV RADIATION

1. G. A. Newkirk: Observations of the Radiation and Polarization of the White Solar Corona (4000-7000 $\AA$ ) at a distance of 1.6-6 solar radii, made from Skylab with a resolution of $8^{\prime \prime}$ (Preliminary information).

2. V. K. Prokof'ev: X-Ray Observations of the Sun by means of the 'Interkosmos' Satellites, the X-Ray spectroheliograms in the region $8-12 \AA$ and high resolution $\left(4 \times 10^{-4} \AA\right)$ spectra in the region 1.8-9.2 $\AA$.

3. R. C. Catura: Large Scale Structure of Solar Active Regions in X-Ray Emission Lines (Rocket Observations on 18 January 1973).

4. J. H. Parkinson: New Observations of the Solar X-Ray Spectrum in the region 9-22 $\AA$ with the Crystal Spectrometer.

5. Sh. Yousef: X-Ray Spectroheliograms and the Fine Structure of the Solar Coronal Active Regions.

6. A. H. Gabriel: Rocket Solar Astronomy (Review).

7. R. M. Bonnet: Balloon IR and UV Solar Astronomy (Review).

8. L. Goldberg on 28 August spoke about the preliminary results of the observations of the Sun from the orbital station Skylab.

\section{STELLAR ASTRONOMY FROM SPACE}

1. H. Lamers: A Short Review of the Symposium 'UV Stellar Radiation' during the COSPAR Meeting in Konstanz in May 1973.

2. A. B. Severny, E. I. Terez and A. M. Zvereva: Preliminary Results Obtained with an Astrophotometer installed on Lunokhod-2 (Read by V. Prokof'ev).

3. A. Monfils, K. Nandy and H. Lamers: ESRO TD-IA Satellite-Spectrophotometric and Spectroscopic Observations in the UV Region by the Sky Scanning Satellite.

4. E. B. Jenkins: A Review of the Technique and Results of the Observations of Interstellar Absorption by the OAO-3 Satellite (Copernicus).

5. R. L. F. Boyd: X-Ray Telescopes on the OAO-3 Satellite (Copernicus). Boyd spoke about the preliminary results obtained with these telescopes during a joint session of Commissions 27 , $40,42,44$ and 48 on 23 August.

6. M. Golay: Balloon Stellar Astronomy, near UV and IR (Review).

7. A. Code: The Current State of the UV Stellar Astronomy from Space and the Main Technical Problems.

8. N. Roman: The Perspectives of the Development of the UV Space Astronomy, the Space Shuttle Program and $3 \mathrm{~m}$ Large Astronomical Telescope (LAS). 